\title{
Introduction: Alpha-Lactalbumin, a Multifunctional Protein that Specifies Lactose Synthesis in the Golgi
}

\author{
Margaret C. Neville
}

Published online: 4 August 2009

(C) Springer Science + Business Media, LLC 2009

Lactose was found in the 1960s [1] to be synthesized by the reaction:

UDP - galactose + glucose $\rightarrow$ lactose + UDP.

Using a protein complex isolated from cow's milk, Kurt Ebner and his colleagues at Oklahoma State University showed that two proteins catalyzed the reaction, galactosyltransferase (Protein $\mathrm{A}$ at the time) and $\alpha$-lactalbumin (Protein B) [2, 3]. Galactosyltransferase was found to have a wide tissue distribution and to catalyze the transfer of $\mathrm{N}$-acetyl-glucosamine residues to glycoproteins [4], but $\alpha$-lactalbumin, which had been known as a milk protein since the early 20 th century [5], was specific to milk and the mammary gland and had a high homology to lysozyme [6]. At very high concentrations of glucose, galactosyltransferase could, by itself, synthesize lactose; however, $\alpha$-lactalbumin was found to bring the glucose $\mathrm{K}_{\mathrm{m}}$ to $\sim 1 \mathrm{mM}$, within the physiological range of glucose concentrations. Work proceeded on the characteristics of the system in several labs, some of which made the very important observation that the lactose synthesis activity was associated with a particulate fraction in the lactating mammary alveolar cell that could represent the Golgi compartment (reviewed in [7]). In 1969 Brew [8] hypothesized that $\alpha$-lactalbumin made its way from the endoplasmic reticulum, where it was synthesized, to the Golgi, where it encountered galactosyltransferase as well as the substrates necessary for lactose synthesis. As the secretory vesicles budded off the Golgi they carried lactose as well as milk proteins such as $\alpha$-lactalbumin to the plasma mem-

M. C. Neville $(\bowtie)$

UCDenver School of Medicine,

Aurora, CO, USA

e-mail: peggy.neville@ucdenver.edu brane for secretion. Linzell and Peaker in their 1971 review [7] realized that this vesicular mechanism solved the problem of the impermeability of lactose to the mammary epithelial cell: Once lactose was synthesized in the Golgi, the sugar could not return to the cytoplasm so, to maintain osmotic equilibrium, water entered the Golgi, causing it to swell and producing the very large vesicles of the terminal Golgi characteristic of the lactating cell.

Nicholas Kuhn, a biochemist at the University of Birmingham, undoubtedly knew of Brew's hypothesis from conversations with Linzell and, of course, a familiarity with the literature gained earlier when he used lactose synthesis in experiments on the role of progesterone as the lactogenic trigger [9]. He set out to do experiments that actually demonstrated, using biochemical techniques, the topology of the reaction in a particulate fraction isolated from rat mammary glands. He showed [10], using fresh cellular fractions at very short times, that the reaction was not inhibited by ovalbumin, an active inhibitor of the soluble enzyme, and that inhibitors of glucose transport inhibited lactose synthesis. These well-controlled experiments, along with the prior observation by Keenan and colleagues that galactosyl-transferase is associated with the Golgi membrane fraction [11], provided convincing evidence for synthesis of lactose within the Golgi compartment.

But research on $\alpha$-lactalbumin did not stop there. Prior to 1975195 articles on $\alpha$-lactalbumin are indexed in Medline; since that time about 2900 articles appear in the index. Many are studies of protein structure or its nutritional relevance as a milk protein. But the protein also has very interesting properties. In 2000 Svensson and colleagues [12] showed that, under low calcium conditions $\alpha$-lactalbumin could bind a specific fatty acid, C18:1, and adopt a altered conformation that induced apoptosis in tumor cells but not in normal cells. This altered protein was called HAMLET 
(human a-lactalbumin made lethal to tumor cells). It seems to enter cells and interact with many intracellular organelles, and, as one might expect, has been proposed as a cancer therapeutic agent [13]. In an entirely different vein, Julie Sharp, Kevin Nicholas, and their co-workers showed that Cape fur seals possessed no lactose in their milk. In addition, they observed that the mammary glands of this species do not involute during long forays into the ocean to feed, leaving a suckling young on the shore [14]. Putting these two observations together they hypothesized in a very recent paper that $\alpha$-lactalbumin in other species initiates involution. Consist with this notion they found that exposure of cultured mammary alveolar cells to $\alpha$-lactalbumin induced apoptosis, leading them to propose that the protein promotes involution-like changes in the weaning mammary gland [15]. How this finding jibes with the lack of effect of HAMLET on normal cells is a question for the future.

\section{References}

1. Watkins WM, Hassid WZ. Synthesis of lactose by particulate enzyme preparations from guinea pig and bovine mammary glands. Science. 1962;136:329.

2. Schanbacher FL, Ebner KE. Galactosyltransferase acceptor specificity of the lactose synthetase A protein. J Biol Chem. 1970;245:5057-61.

3. Fitzgerald DK, Brodbeck U, Kiyosawa I, Mawal R, Colvin B, Ebner KE. Alpha-lactalbumin and the lactose synthetase reaction. J Biol Chem. 1970;245:2103-8.
4. Brew K, Hill RL. Lactose biosynthsis. Rev Physiol Biochem Pharmacol. 1975;72:103-58.

5. Woods DE. The combination curves, hydrogen ion regulating powers and equivalents of lactalbumin, and its non-identity with serum-albumin. Biochem J. 1934;28:2034-8.

6. Brew K, Vanaman TC, Hill RL. Comparison of the amino acid sequence of bovine alpha-lactalbumin and hens egg white lysozyme. J Biol Chem. 1967;242:3747-9.

7. Linzell JL, Peaker M. Mechanism of milk secretion. Physiol Rev. 1971;51:564-97.

8. Brew K. Secretion of alpha-lactalbumin into milk and its relevance to the organization and control of lactose synthetase. Nature. 1969;222:671-2.

9. Kuhn NJ. Progesterone withdrawal as the lactogenic trigger in the rat. J Endocrinol. 1969;44:39-54.

10. Kuhn NJ, White A. The topography of lactose synthesis. Biochem J. 1975;148:77-84.

11. Keenan TW, Huang CM, Morre DJ. Membranes of mammary gland. V. Isolation of Golgi apparatus and rough endoplasmic reticulum from bovine mammary gland. J Dairy Sci. 1972;55:1577-85.

12. Svensson M, Hakansson A, Mossberg AK, Linse S, Svanborg C. Conversion of alpha-lactalbumin to a protein inducing apoptosis. Proc Natl Acad Sci U S A. 2000;97:4221-6.

13. Hallgren O, Aits S, Brest P, Gustafsson L, Mossberg AK, Wullt B, et al. Apoptosis and tumor cell death in response to HAMLET (human alpha-lactalbumin made lethal to tumor cells). Adv Exp Med Biol. 2008;606:217-40.

14. Sharp JA, Cane KN, Lefevre C, Arnould JP, Nicholas KR. Fur seal adaptations to lactation: insights into mammary gland function. Curr Top Dev Biol. 2006;72:275-308.

15. Sharp JA, Lefevre C, Nicholas KR. Lack of functional alphalactalbumin prevents involution in Cape fur seals and identifies the protein as an apoptotic milk factor in mammary gland involution. BMC Biol. 2008;6:48. 